\title{
Multiple meningiomas in a dog: a case report
}

\author{
Lise A Daniaux, Beverly K Sturges ${ }^{1}$, Allison L Zwingenberger ${ }^{1}$ \\ William R. Pritchard Veterinary Medical Teaching Hospital, School of Veterinary Medicine, University of \\ California, Davis, CA 95616, USA; 1. Department of Surgical and Radiological Sciences, School of Veterinary \\ Medicine, University of California, Davis, CA 95616, USA \\ Corresponding author: Allison L Zwingenberger, email: azwingen@ucdavis.edu \\ Received: 28-03-2012, Accepted: 16-04-2012, Published Online: 22-05-2012 \\ doi: $10.5455 /$ vetworld.2012.495-498
}

\section{To cite this article:}

Daniaux LA, Sturges BK, Zwingenberger AL (2012) Multiple meningiomas in a dog: a case report, Vet World 5(8): 495-498. doi: 10.5455/vetworld.2012.495-498

\section{Introduction}

Meningioma is a common intracranial tumor encountered in dogs and cats [1,2], and represents approximately 30 to $45 \%$ of all reported canine intracranial tumors [3] Dolichocephalic dogs were overrepresented in 2 studies, including German shepherd dogs, golden retrievers and boxers [1,2]. Meningiomas are more commonly reported in middle to older age dogs $[1,2]$. Some articles revealed a female sex predilection [1]. Multiple meningioma is common in cats representing approximately $17 \%$ of all reported feline meningiomas [4]. However it is rarely reported in dogs [2,5].

\section{Case history}

An 11 year old female spayed, shepherd mix dog presented to the Veterinary Medical Teaching Hopsital at UC Davis for three generalized seizures in the previous 12 days. The dog had been diagnosed two years earlier with vertebral column plasma cell tumor and had undergone a T11 decompression and stabilization procedure for the treatment of a pathological fracture and myelopathy at that time. Chemotherapy, consisting of melphalan and prednisone, was administered for the following 14 months until the dog developed marked thrombocytopenia. All medications were stopped and the dog remained free of neurological signs and in remission from the tumor.

\section{Clinical diagnosis}

The physical examination was unremarkable. Neurological examination on the day of presentation revealed an ambulatory patient with generalized ataxia and tetraparesis. Proprioceptive positioning was delayed, worse on the left side and in the pelvic limbs. Mentation was appropriate, and cranial nerve examination was within normal limits. The segmental reflexes were also within normal limits. A neuroanatomic localization was made to the cerebrum.

In preparation for the MRI examination, the dog was premedicated with Oxymorphone $(0.05 \mathrm{mg} / \mathrm{kg})$ and Atropine $(0.02 \mathrm{mg} / \mathrm{kg})$ subcutaneously, followed by intravenous administration of propofol (1.5 $\mathrm{mg} / \mathrm{kg}$ ). The dog was intubated and anesthesia was maintained with a constant rate infusion of Fentanyl $(0.5 \mu \mathrm{g} / \mathrm{kg} / \mathrm{min})$ and propofol $(0.2 \mathrm{mg} / \mathrm{kg} / \mathrm{min})$. Magnetic resonance imaging was performed using a 1.5 Tesla MR unit (General Electric MR Signa LX, General Electric Co., Milwaukee, WI). On precontrast T1 images, a small rounded mass like lesion measuring approximately $1 \mathrm{~cm}$, located at the periphery of the right frontal lobe, was identified. This mass was slightly hyperintense to the white mater on $\mathrm{T} 1$ weighted images and hyperintense to the white matter on T2 weighted images. A marked hyperintense signal on T2 and FLAIR weighted images was present surrounding the mass rostrally and caudally, tracking through the white matter. The T2 and FLAIR hyperintense signal could be followed rostrally towards the region of the right olfactory peduncle. A mass effect was present in the region of the primary mass with leftward deviation of the falx cerebri and ventral compression of the lateral ventricles (Figure-1).

On T1 weighted images following intravenous administration of gadopentate dimeglumine (0.1 $\mathrm{mmol} / \mathrm{kg}$, Magnevist, Bayer HealthCare Pharmaceuticals Inc., Wayne, NJ), the mass lesion in the right frontal lobe strongly and homogeneously contrast enhanced. A second smaller extra-axial mass was 

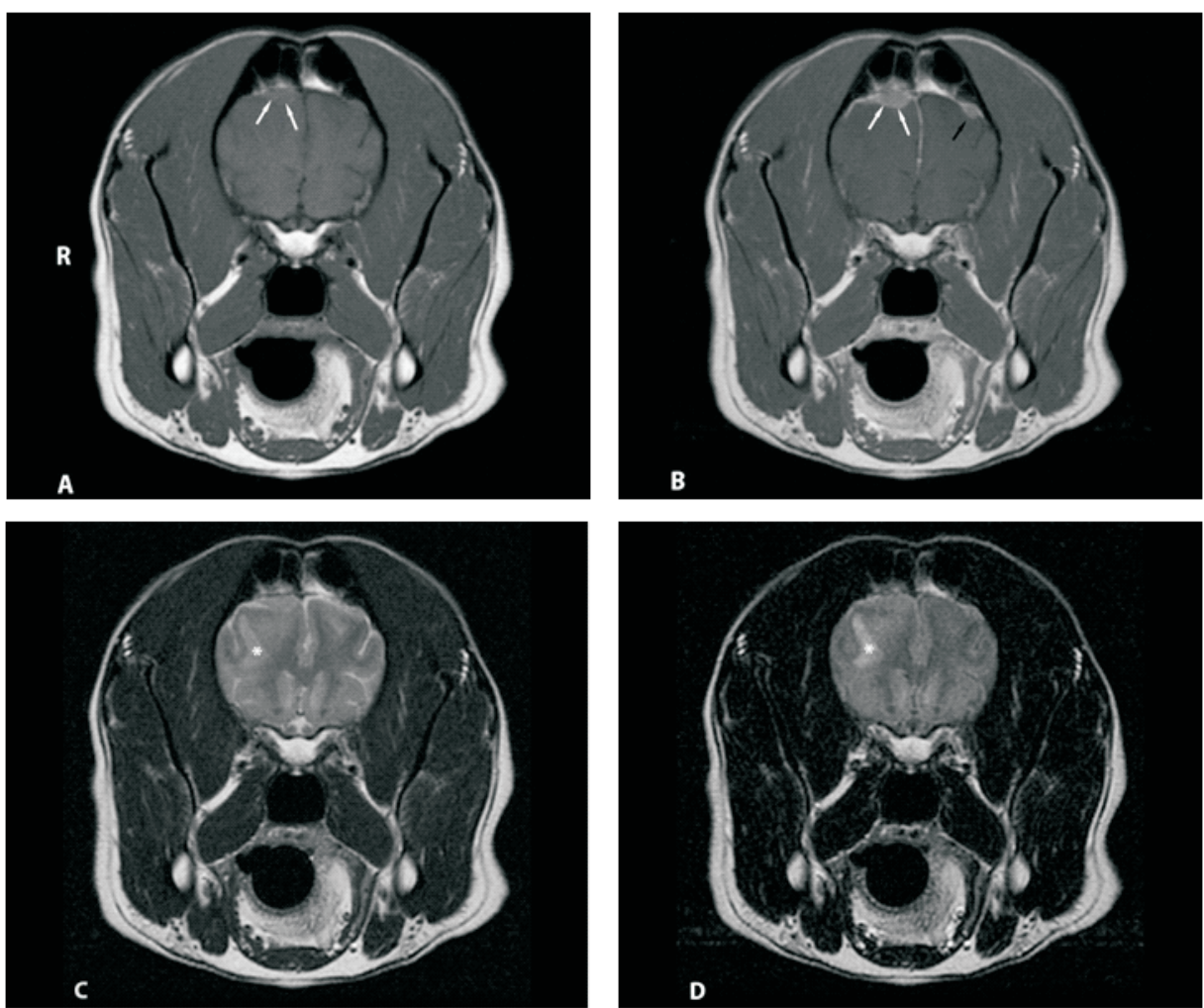

Figure-1. Transverse MR images of the brain at the level of the rostral frontal lobe. T1 weighted image (A), T1 weighted image after contrast media administration (B), T2 weighted image (C), and FLAIR weighted image (D). (A) The largest mass is visible as a slight T1 hyperintensity in the frontal lobe (white arrows), and a mass effect is shifting the falx cerebri to the left. (B) After contrast administration, the mass on the right is strongly contrast-enhancing. A second dural mass is visible in the left frontal lobe (black arrow). Well defined dural tails are visualized. (C,D) A moderate amount of hyperintense signal in the white matter $(*)$ is present, representing edema.

identified in the left frontal lobe and a third mass was identified at the caudodorsal aspect of the right olfactory peduncle. For each of the masses, the meninges contiguous with and tapering away from the mass were contrast enhancing, representing a dural tail sign. The masses appeared to be separate in location. Based on the imaging findings of multiple extra-axial masses, a tentative diagnosis of multiple meningiomas was established. Other differential diagnosis included a recurrence of the previous multiple myeloma, lymphosarcoma, histiocytic sarcoma or dural metastases.

\section{Treatment}

A craniotomy was performed to remove the intracranial masses on the left side (frontal lobe and olfactory bulb). The patient was positioned in sternal recumbency with the head elevated. The anesthetic protocol used for the MRI was continued. The patient received an intra-operative IV bolus of mannitol $(0.5 \mathrm{mg} / \mathrm{kg})$ during the surgery due to acute brain swelling following opening of the dura mater. Two of the tumors were surgically removed through combined transfrontal and rostrotentorial approaches to the brain. Mass removal was accomplished using ultrasonic aspiration. Following removal, the dural defect was repaired using a temporalis muscle graft obtained from the right temporalis muscle. A skull cap, fashioned from polymethylmethacrylate, was used to cover the bony defect in the frontal/parietal bones . The patient recovered well after the surgery and no further seizures were noted. The histopathologic diagnosis was meningioma of mixed psammomatous and transitional subtypes.

\section{Discussion}

Multiple meningioma is a rare condition in small animals. [2,5]. In the human literature, multiple meningiomas are frequently encountered in neurofibromatosis type II. Neurofibromatosis type II is an autosomal dominant neurocutaneous disorder which 


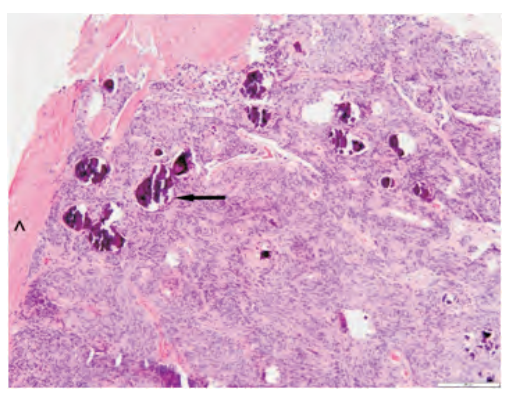

usually develops in adult patients. It manifests as development of multiple central nervous system tumors. The patients generally develop bilateral vestibular schwannomas with additional intracranial, intraspinal tumors such as meningioma, glioma and ependymoma. These conditions have not been recognized in dogs to date [6-8].

The clinical signs associated with multiple meningiomas vary depending on the location, growth rate and secondary effects. Seizures and decreased activity level, as well as behavioral changes, are frequently reported. [5,9] In our patient, seizures, proprioceptive deficits, and generalized ataxia correlated with the location of the masses.

The origin of multiple meningioma is unclear, however multiple meningiomas may represent multicentric disease or may represent local metastasis from a single lesion. In a previous article, the multiple meningeal masses were located on the same side of the brain.[5] In the present case the masses involved meninges on both sides of the brain. All the masses were localized in the supratentorial fossa as in the previous case report [5].

On MRI, meningiomas are usually iso-to hypointense compared to the gray matter on $\mathrm{T} 1$ weighted images, and are hyperintense to isointense to the gray matter on T2 weighted images $[2,5,10,11]$. They usually have a broad base and rounded appearance and occur along the falx cerebri or the meninges. After contrast administration, the majority of meningiomas diffusely, strongly contrast enhance and have sharp margins. The contrast enhancement pattern may vary due to the presence of cysts or necrosis within the meningeal mass, or mineralization within the tumor (i.e. psammoma bodies). On T2 and FLAIR weighted images, a large amount of hyperintense signal was noted in the white matter surrounding the masses and represented peritumoral edema (Figure-1). This finding is common in meningioma. It is more frequently encountered with masses located in the olfactory peduncles and frontal lobes of the cerebrum [2].
A dural tail sign can frequently be appreciated at the margin of the meningioma after contrast administration in dogs[2] and cats [4]. On post contrast T1 weighted images, the dural tail sign is identified as a thickening of the dura adjacent to an intracranial pathology. Also known as meningeal sign, it is generally reported with meningioma however it is not pathognomonic for meningioma and may be associated with other extra-axial pathologies such as lymphoma, and dural metastasis [12]. The pathophysiology of the dural tail sign is complex and not fully established in the human literature. Invasion of the dural vessels by tumor cells and packing at the point of tumor attachment, reactive hypervascularity and tumoral invasion of the dura are three suspected pathophysiologies of dural tail sign [12].

Multiple therapeutic options are available for treatment of multiple meningiomas. The current treatment recommendations include surgery and/or radiation therapy[13]. The most appropriate choice of therapy usually depends on the localization of the masses and their biological behavior.

\section{Conclusion}

In conclusion, multiple meningioma is a rare intracranial tumor that appears to be limited to cranial and middle cranial fossa. The clinical signs, MR features, and recommended treatment are similar to a single intracranial meningioma.

\section{References}

1. Patnaik AK, Kay WJ and Hurvitz AI (1986) Intracranial meningioma: a comparative pathologic study of 28 dogs. Vet Pathol 23(4): 369-373.

2. Sturges BK, Dickinson PJ, Bollen AW, Koblik PD, Kass PH, Kortz GD, Vernau KM, Knipe MF, LeCouteur RA and Higgins RJ (2008) Magnetic Resonance Imaging and Histological Classification of Intracranial Meningiomas in 112 Dogs. J Vet Intern Med 22(3): 586-595.

3. Long S (2006) Neoplasia of the nervous system. In: (Ed.) $\mathrm{VCH}$, editor. Braund's clinical neurology in 
small animals:localization, diagnosis and treatment. St Louis: Mosby.

4. Troxel MT, Vite CH, van Winkle TJ, Newton AL, Tiches D, Dayrell-Hart B, Kapatkin AS, Shofer FS and Steinberg SA (2003) Feline Intracranial Neoplasia: Retrospective Review of 160 Cases (1985-2001). J Vet Intern Med 17(6): 850-859.

5. McDonnell JJ, Kalbko K, Keating JH, Sato AF and Faissler D (2007) Multiple Meningiomas in Three Dogs. J Am Anim Hosp Assoc 43(4): 201-208.

6. Evans DG, Sainio M and Baser ME (2000) Neurofibromatosis type 2.JMed Genet 37(12): 897-904.

7. Evans DG (2009) Neurofibromatosis 2 [Bilateral acoustic neurofibromatosis, central neurofibromatosis, NF2, neurofibromatosis type II]. Genet Med 11(9): 599-610.

8. Mautner VF, Tatagiba M, Lindenau M, Funsterer C, Pulst SM, Baser ME, Kluwe L and Zanella FE (1995) Spinal tumors in patients with neurofibromatosis type 2: MR imaging study of frequency, multiplicity, and variety. AJR Am J Roentgenol 165(4): 951-955.

9. Mercier M, Heller HL, Bischoff MG, Looper J and Bacmeister CX (2007) Imaging diagnosishyperostosis associated with meningioma in a dog. Vet Radiol Ultrasound 48(5): 421-423.

10. Kraft SL, Gavin PR, DeHaan C, Moore M, Wendling LR and Leathers CW (1997) Retrospective review of 50 canine intracranial tumors evaluated by magnetic resonance imaging. J Vet Intern Med 11(4): 218-225.

11. Wisner ER, Dickinson PJ and Higgins RJ (2011) Magnetic resonance imaging features of canine intracranial neoplasia. Vet Radiol Ultrasound 52 (Suppl 1): S52-61.

12. Sotoudeh H and Yazdi HR (2010) A review on dural tail sign. World JRadiol 2(5): 188-192.

13. Axlund TW, McGlasson ML and Smith AN (2002) Surgery alone or in combination with radiation therapy for treatment of intracranial meningiomas in dogs: 31 cases (1989-2002). J Am Vet Med Assoc 221(11): 1597-1600. 